\title{
Teacher Enthusiasm and Student Motivation for Learning
}

\author{
David Palmer \\ School of Education, University of Newcastle \\ University Drive, Callaghan, NSW, 2308, Australia
}

Tel: 612-4921-5715 E-mail: david.palmer@ newcastle.edu.au

Received: February 6, 2020

Accepted: March 27, 2020

Published: April 20, 2020

doi:10.5296/gjes.v6i1.16405

URL: https://doi.org/10.5296/gjes.v6i1.16405

\begin{abstract}
Previous studies of teacher enthusiasm have indicated that it can influence student motivation for learning, but it is not yet clear whether all students are influenced in this way, or only some of them. This study aimed to identify the percentage of students who were influenced by the teacher's enthusiasm in normal classroom settings. Twenty-four grade 10 students were individually interviewed. The results indicated that all of the students had been influenced by the teacher's enthusiasm, or lack of enthusiasm, in a recent lesson. Furthermore, the students described a wide range of teacher behaviors that they interpreted as indicating teacher enthusiasm. It was concluded that teacher enthusiasm is a motivational factor that can influence all or nearly all students.
\end{abstract}

Keywords: Enthusiasm, Motivation, Behavior 


\section{Introduction and Literature Review}

Kunter, Tsai, Klusmann, Brunner, Krauss, and Baumert (2008) argued that "there is no single, widely accepted definition of the concept of enthusiasm ... [but] in everyday language, the word 'enthusiasm' describes the enjoyment and excitement that people experience when engaged in certain tasks" (p. 468). They argued that "enthusiasm can be conceptualized as a relatively stable affective disposition that may be seen as an integral part of teachers' motivation" (p. 469) which is reflected in high quality instructional behaviour.

A comprehensive review of teacher enthusiasm was carried out by Orosz, Tóth-Király, Bőthe, Kusztor, Kovács, and Jánvári (2015). They reported the difficulties of accurately defining enthusiasm, and concluded that the term can be defined in terms of either behaviour (including energetic and stimulating gestures, facial expressions and vocal delivery) or as an internal state which is a personal characteristic of the individual. These authors focused on the behavioural form of enthusiasm, since it included externally visible behaviors such as an engaging manner when presenting content in the classroom, and teacher engagement in warm interactions with students. Similarly, Keller, Neumann, and Fischer (2013) reported eight indicators of enthusiasm among teachers: "using demonstrative gestures; movements of the body and in space; exhibiting a lively facial expression; choosing highly descriptive and illustrative words; being eager in accepting students' ideas and feelings; and maintaining general vitality and drive throughout the lesson" (p. 247).

Kunter et al (2008) reported that "teacher enthusiasm is usually inferred from observations of teachers' instructional behaviors, such as remarking on the value of the learning material or expressing their own interest in the matter" (p. 469). Keller, Neumann, and Fischer (2013) argued that "a teacher is perceived as being enthusiastic when he or she succeeds in communicating excitement about the subject to students" (p. 247).

The purpose of this study was to investigate the proportion of students who are influenced by the teacher's enthusiasm.

\subsection{Types of Enthusiasm}

Kunter, Tsai, Klusmann, Brunner, Krauss, and Baumert (2008) distinguished between teacher enthusiasm for subject matter and teacher enthusiasm for teaching that subject matter. Mitchell (2013) provided a number of examples of enthusiasm for subject matter: "Preparation before the lesson or unit even begins is one important way to model enthusiasm ... painting a verbal picture of what is to come works for some eloquent teachers ... sharing personal stories of how meaningful the activity has been in their lives ... Enthusiasm for content can also be demonstrated through planning, and a thoughtful sequence of learning experiences" (p. 20). More recently, Wenstrom, Uusiautti, and Maatta (2018) reported that teacher enthusiasm was manifested by a willingness to enhance their expertise and skills in the workplace.

On the other hand, teacher enthusiasm for teaching the subject matter can be evidenced when the "teacher communicates a genuine pleasure for the presence of the students. This communication begins with welcoming students to the instructional setting and continues 
with verbal and nonverbal interactions with students throughout the lesson - accepting ideas and feelings expressed by students, praising students, and providing positive feedback on their actions during the class" (Mitchell, 2013, p. 20).

\subsection{Importance of Teacher Enthusiasm}

Enthusiasm is "a key determinant of effective teaching ... [and is] a desirable and defining characteristic of good teachers" (Keller et al., 2013, p. 247). Orosz et al. (2015) reported that teacher enthusiasm is important because of its effects on students. They reported that the more often teachers use gestures, movement, eye contact and variation in voice, the higher were the achievements of pupils. In general, positive teacher enthusiasm was found to lead to high achievement among their pupils and included positive outcomes such as on-task behaviour, recall of information, and higher test scores. They concluded that there was a causal link between teacher enthusiasm and achievement.

Researchers have also reported a link between teacher enthusiasm and student motivation. Minchella (2007) reported that "passion motivates students and motivated students learn ... An enthusiastic, flexible lecture style ... helps maintain student engagement" (p. 12). Kunter et al. (2008) reported a similar conclusion: "a small number of experimental studies have investigated the effect of different levels of instructor enthusiasm on students' motivations and learning behaviors, typically by having lecturers display different levels of expressiveness in controlled instructional settings ... These studies show that teachers who display high levels of enthusiasm or intrinsic motivation to teach seem to exert a positive effect on students' own motivation" (p. 469).

Finally, Keller, Neumann, and Fischer (2013) reported that teacher enthusiasm not only positively influences students' achievement and intrinsic motivation, but it also influences their on-task behaviour. Similarly, data provided by Chang (2014) revealed how important teacher enthusiasm is for developing a positive attitude among students and building cohesiveness in the group, along with positive group norms.

The implications of teacher enthusiasm may even become increasingly important in future years. Paldy (2013) argued that massive open online courses (MOOCs) "are not likely to substitute for personal interactions among students and teachers because enthusiasm and intellectual passion may be difficult to transmit electronically" (p. 6). Similarly, Freudenberg and Samarkovski (2014) argued that "academics today face an array of challenges to their enthusiasm, including teaching students from diverse backgrounds with wavering levels of engagement with their studies ... This could result in unfavourable outcomes, as an academic's lack of enthusiasm may have an adverse impact on students learning, may also affect their own wellbeing and, ultimately, be detrimental to the institution they work for" ( $\mathrm{p}$. 22).

\subsection{Why does Teacher Enthusiasm have Positive Effects on Students?}

Orosz et al. (2015) reported two possible reasons why teacher enthusiasm can have positive effects on students. First, students tend to pay attention to a greater extent when teachers use gestures that are demonstrative and varied, with dramatic vocal delivery and body 
movements. For example, Keller et al. (2013) reported that "This explanation is especially likely when enthusiastic behaviors are defined mainly as expressive, nonverbal behaviors because the attention-commanding role of such behaviors is established" (p. 248).

Second, enthusiasm can be transmitted to students by a process known as emotional contagion. This occurs when "the emotions and behaviors of one person can influence the emotions and behaviors of others (Mitchell, 2013). According to Bakker (2005) emotional contagion occurs when positive or negative emotions cross over from one individual to another. He reported the definition of emotional contagion as being "the tendency to automatically mimic and synchronize facial expressions, vocalizations, postures and movements with those of another person and consequently to converge emotionally" (p. 30). Bakker (2005) provide evidence that "our emotions are influenced by those of others whether we like the others or not, and whether we want to or not" (p. 30). This suggests that, as enthusiasm is a positive emotion, so an enthusiastic teacher might have a positive influence on student enthusiasm.

Interestingly, it has been proposed that there is a reciprocal relationship involved in teacher enthusiasm. Keller et al. (2013) stated that "the reverse effect of student achievement and motivation on teachers' enthusiasm seems intuitive: a teacher, who is confronted with highly interested, motivated high-achievers, would be presumably more enthusiastic than a teacher confronted with less interested, lower achieving students" (p. 248).

\section{The Present Study}

The previous studies have indicated that enthusiasm can be an important component of a teacher's professional disposition (Wenstrom, Uusiautti, \& Maatta, 2018). However, it has not yet been established whether all students perceive and are affected by teacher enthusiasm, or just some of them. The present study has two aims:

1). What proportion of students are influenced by teacher enthusiasm?

2). What are the indicators of teacher enthusiasm as perceived by students?

\section{Methodology}

Data were collected using individual interviews with grade 10 students. The data reported in this paper were part of a larger study.

\subsection{Participants}

The participants were 24 (15-16 year-old) students who volunteered to participate. They attended three secondary schools in a small city in New South Wales, Australia. Each school included students from a range of socioeconomic backgrounds. Eight students from each school participated in the study. In these schools, students with higher achievement had been placed in upper stream classes, whereas those with lower achievement had been placed in lower stream classes. The sample from each school was stratified, because it included two boys and two girls from high stream classes and two boys and two girls from low stream classes. 


\subsection{Interview Procedure}

The researcher individually interviewed each student. The interviews were carried out at a quiet location at the school during school hours. The duration of the interview was roughly 15 minutes. The interview was in two parts, as follows.

Part A. Each participant was asked to bring to mind a recent lesson in which he/she had experienced a positive feeling of wanting to learn. Each student was then asked the following questions:

1). Was teacher enthusiasm a factor that influenced your interest in that lesson?

2). How could you tell whether your teacher was enthusiastic or not enthusiastic?

Part B. Each participant was then asked to bring to mind another recent lesson in which he/she had experienced a negative feeling of not wanting to learn. Each student was then asked the following questions:

1). Was teacher enthusiasm a factor that influenced your interest in that lesson?

2). How could you tell whether your teacher was enthusiastic or not enthusiastic?

\subsection{Analysis}

A combination of quantitative and qualitative techniques were used. Qualitative techniques involving the coding of students' statements were used to categorize the responses to interview Questions 1 and 2. Instances of positive or negative teacher enthusiasm were also coded. The descriptive statistics were used to calculate the percentage of students in each category.

\section{Results}

\subsection{Was Teacher Enthusiasm a Factor that Had Influenced Student Motivation in That} Lesson?

In response to Part A of the interview (i.e., the lesson in which the student had experienced a positive feeling about learning) almost every student in this study (96\%) indicated that teacher enthusiasm had been a factor that influenced their disposition. In $96 \%$ of cases, the students reported that the teacher had displayed positive enthusiasm. However, there was one case in which the teacher had not been enthusiastic but the student had nevertheless remained interested in the lesson.

In response to Part B of the interview (i.e., the lesson in which the student had experienced a negative feeling about learning) all (100\%) of the students indicated that they had been influenced by the teacher's enthusiasm or lack of enthusiasm. A substantial portion (29\%) of the students indicated that their teacher had not been enthusiastic and this had negatively affected their own disposition in that lesson. The remainder (71\%) indicated that the teacher had been enthusiastic, but this had not been enough to create a positive disposition towards that lesson, among these students. 


\section{Macrothink}

Global Journal of Educational Studies

ISSN 2377-3936

2020, Vol. 6, No. 1

Students' comments confirmed that the teacher's enthusiasm did have an impact on their disposition towards the lesson:

- "Yea, if he walks into the classroom and is happy, I get happy and it's a good lesson".

- "Yes, it just makes me feel good and they want us to learn instead of being all dull and stuff".

- "[The teacher] likes it and then you like it".

- [Interviewer: Was the teacher enthusiastic?] "Yes, she did". [Interviewer: Did that help you to feel enthusiastic as well?] "Yes, it did actually".

\subsection{How could You Tell Whether Your Teacher Was Enthusiastic?}

The students described several teacher behaviors that they interpreted as indicating teacher enthusiasm. These included,

- Smiling (e.g., "When [the teacher] walks into a classroom and they have a happy vibe in them and they start the lesson with a happy smile and they're not all grumpy".)

- Greeting the class (e.g., "When I walked in she was like 'Good morning class. How are you?' and she'd start talking about the topic".)

- Explaining concepts clearly (e.g., "She's trying to explain it to us so we can learn").

- Answering questions from students (e.g., "[The teacher] answers questions and they ask people 'What do you want to know?' If you've got a problem he'll just answer it”.)

- Having a good knowledge of the topic (e.g., "When [the teacher] can talk about it without looking at notes and they answer questions and they welcome questions".)

- Explaining and re-explaining (e.g., "When he's explaining he goes into depth and if someone doesn't get it he'll try to explain it again".)

- Generating a positive atmosphere in the classroom (e.g., "She was always coming to class really happy. Making our class atmosphere for us".)

- Showing emotion about the content (e.g., "Even when we watched a video she was very into it. She even cried a little bit because of the veterans".)

- Asking if people are understanding (e.g., "Yes, because she singles people out and asks them if they're understanding it" [Interviewer: She helps you when you don't understand?] "Yes".)

- Interacting with the students (e.g., "[The teacher] tries to interact with the students as much as they can".)

- Being encouraging (e.g., "He's just trying to get us awake and 'Come on guys you can do it. Just give it a go"”.) 
- Being inclusive (e.g., “He’s not leaving anyone out. He wants everyone to learn”.)

- Using humor (e.g., "He goes through it. He might have a joke".)

Conversely, the students described several teacher behaviors that indicated lack of enthusiasm. These included:

- Lack of help from the teacher (e.g., "She just gives up and just goes and sits down and doesn't help us".)

- Not checking whether students have understood (e.g., "He'll kind of just say it and expect us to process it".)

- Lack of interaction (e.g., "She just teaches it. Writes it on the board. Gives you worksheets. That's it".)

- Not being inclusive (e.g., "He sees me having no interest in it, so he helps the kids that actually have an interest in it".)

- Not making an attempt to display interest (e.g., "She's not very enthusiastic. When she talks she doesn't seem very interested in it. She usually just writes stuff up on the board and we have to copy it down in our book".)e

\section{Discussion and Conclusions}

The first purpose of this study was to investigate whether teacher enthusiasm was a factor that influenced the way students felt about learning, and if so, to identify the proportion of students who were influenced in this way. It was found that $96 \%$ of the students had been influenced by the teacher's enthusiasm or lack of enthusiasm in both of the lessons (i.e., the lesson in which they had experienced a positive motivation for learning, as well as the lesson in which they had not experienced a desire to learn. The one remaining student (4\%) had been influenced by the teacher's enthusiasm in one lesson but not the other. Thus, $100 \%$ of the students reported being influenced by the teacher's enthusiasm or lack of enthusiasm in one or both of the lessons. This is a very important finding because it suggested that teacher enthusiasm had an influence on all or nearly all students. In previous studies of teacher enthusiasm, the emphasis has been on identifying the characteristics or effects of teacher enthusiasm (Orosz et al., 2015) but the actual proportions of students who are influenced has not been apparent. The present study has provided evidence to fill this apparent gap in the literature.

This study used a stratified sample of students that included equal numbers of males and females, as well as equal numbers of students from upper and lower achievement levels. Yet there were no apparent differences between any of these groups. This was an interesting finding because previous studies have indicated that male and female students can differ in their motivations, interests, and engagement (Wang \& Degol, 2017). Yet it is difficult to find any previous study that has investigated differential effects of teacher enthusiasm on male and female students, or students from upper and lower achievement levels. Thus, the contribution of the present study suggests that teacher enthusiasm can have an effect of 
student desire to learn regardless of the students' gender or achievement level.

Previous studies have suggested that the process by which teacher enthusiasm can influence students can either be by (1) demonstrative and varied gestures and vocal deliveries that capture the attention of students, or (2) by emotional contagion, in which an emotion expressed by a teacher influences the emotions of the students (Keller et al., 2013; Mitchell, 2013). The second of these two proposals, emotional contagion, appears to be supported by the findings of the present study. Several of the students commented that when the teacher expressed a positive enthusiasm, happiness or other positive emotion, it influenced them to have a more positive emotion. The following are some examples, with emotive words emphasized,

- "Yea, if he walks into the classroom and is happy, I get happy and it's a good lesson".

- "It just makes me feel good and [the teacher] wants us to learn instead of being all dull and stuff".

- "[The teacher] likes it and then you like it".

By contrast, none of the students mentioned that the teacher's expressive gestures or vocal intonations had captured their attention. Thus, the present study provides support for the idea that emotional contagion is at work when students become influenced by the teacher's enthusiasm.

However, there was one type of instance in which emotional contagion did not occur. The results from Part B of the interview suggested that $71 \%$ of students had experienced a lesson in which the teacher had been enthusiastic, but this had not been enough to create a positive desire to learn in that lesson, among these students. One possible explanation for this finding is that factors other than teacher enthusiasm had also been influencing the students on those occasions, and if these other factors had been negative in their effect then they may have overridden the positive effects of teacher enthusiasm on those occasions. Examples of negative factors that may have been relevant include the possibility of students with lack of interest in the content or lack of confidence (Ainley, Hidi, \& Berndorff, 2002).

The second purpose of the study was to investigate the indicators of teacher enthusiasm - in other words, to answer the question of how students decide if a teacher is enthusiastic. The results showed that students identified such teacher behaviors as smiling, greeting the class, explaining concepts clearly, answering questions from students, having a good knowledge of the topic, explaining and re-explaining, generating a positive atmosphere in the classroom, showing emotion about the content, asking students if they are understanding, interacting with students, being encouraging, being inclusive, and using humor, as being indicators of teacher enthusiasm. Interestingly, none of the students mentioned stimulating gestures, facial expressions or varied vocal delivery, which was surprising because these are thought to be common indicators of teacher enthusiasm (Orosz et al., 2015). Conversely, several of the behaviors identified in the present study do not appear to have been widely recognized in the literature: including smiling, answering questions from students, having a good knowledge of the topic, explaining and re-explaining, generating a positive atmosphere in the classroom, 
asking students if they are understanding, being encouraging, and being inclusive to all students. This indicates that we still have very much to learn about the indicators of teacher enthusiasm.

It was also apparent that some students in the present study had experienced teachers who were less than enthusiastic. Behaviors such as a teacher not helping students, not checking whether students have understood, lack of interaction with students, not being inclusive to all the students in the class, and not making an attempt to display interest, were all indicative of low teacher enthusiasm. Significantly, these teacher behaviors were almost always associated with lessons in which students experienced little or no desire to learn. This finding indicates that it is not only important to investigate the characteristics of positive teacher enthusiasm, as has previously been the case (Orosz et al., 2015), but also the characteristics and effects of low teacher enthusiasm.

In conclusion, this study has provided evidence that teacher enthusiasm is a motivational factor that has the potential to influence all or nearly all students, in classroom situations. This can apply regardless of student gender or achievement level. The study also suggested that there is a very wide range of teacher behaviors that students can interpret as indicators of teacher enthusiasm, and finally, it is important to emphasize that teachers' lack of enthusiasm is also evident to students and can negatively impact their desire to learn.

\section{References}

Ainley, M., Hidi, S., \& Berndorff, D. (2002). Interest, learning, and the psychological processes that mediate their relationship. Journal of Educational Psychology, 94, 545-561. https://doi.org/10.1037/0022-0663.94.3.545

Bakker, A. B. (2005). Flow among music teachers and their students: The crossover of peak experiences. Journal of Vocational Behavior, 66, 26-44. https://doi.org/10.1016/j.jvb.2003.11.001

Chang, L. Y. H. (2014). Characteristics of motivated L2 class groups: From language teachers' and students' perspectives. English Language Teaching, 7, 159-167. https://doi.org/10.5539/elt.v7n7p159

Freudenberg, B., \& Samarkovski, L. (2014). Enthusiasm and the effective modern academic. Australian Universities' Review, 56, 22-31.

Keller, M. M., Neumann, K., \& Fischer, H. E. (2013). Teacher enthusiasm and student learning. Retrieved from https://www.researchgate.net/publication/277015929

Kunter, M., Tsai, Y. M., Klusmann, M., Brunner, M., Krauss, S., \& Baumert, J. (2008). Students' and mathematics teachers' perceptions of teacher enthusiasm and instruction. Learning and Instruction, 18, 468-482. https://doi.org/10.1016/j.learninstruc.2008.06.008

Minchella, D. J. (2007). R.E.S.P.E.C.T. - A teaching primer. Journal of College Science Teaching, 36, 12-13.

Mitchell, M. (2013). Teacher enthusiasm: Seeking student learning and avoiding apathy. 


\section{Macrothink}

Global Journal of Educational Studies

ISSN 2377-3936 2020, Vol. 6, No. 1

Journal of Physical Education, Recreation \& Dance, 84, 19-24. https://doi.org/10.1080/07303084.2013.779536

Orosz, G., Tóth-Király, I., Bőthe, B., Kusztor, A., Kovács, Z., \& Jánvári, M. (2015). Teacher enthusiasm: A potential cure of academic cheating. Frontiers in Psychology, 6(318), 1-12. https://doi.org/10.3389/fpsyg.2015.00318

Paldy, L. G. (2013). MOOCs in your future. Journal of College Science Teaching, 42, 6-7.

Wang, M., \& Degol, J. L. (2017). Gender gap in science, technology, engineering, and mathematics (STEM): Current knowledge, implications for practice, policy, and future directions. Educational Psychology Review, 29, 119-140. https://doi.org/10.1007/s10648-015-9355-X

Wenstrom, S., Uusiautti, S., \& Maatta, K. (2018). "The force that keeps you going": Enthusiasm in vocational education and training (VET) teachers' work. International Journal for Research in Vocational Education and Training, 5(4), 244-263. https://doi.org/10.13152/IJRVET.5.4.1

\section{Copyright Disclaimer}

Copyright for this article is retained by the author(s), with first publication rights granted to the journal.

This is an open-access article distributed under the terms and conditions of the Creative Commons Attribution license (http://creativecommons.org/licenses/by/3.0/). 